\title{
Evaluation of risk factors and treatment options in patients with ureteral stricture disease at a single institution
}

\author{
Henry Tran, MD; Olga Arsovska, BSc; Ryan F. Paterson MD; Ben H. Chew, MD \\ University of British Columbia, Vancouver, BC, Canada
}

Cite as: Can Urol Assoc J 2015;9(11-12):E921-4. http://dx.doi.org/10.5489/cuai.3057

Published online December 14, 2015.

\section{Abstract}

Introduction: Ureteral strictures are a significant cause of morbidity and mortality, resulting in potential kidney damage requiring several surgical procedures. Non-malignant causes include radiation, trauma from calculi impaction, pelvic surgery, or ureteroscopy (URS). We identified risk factors in our patients with ureteral strictures and the success of their treatment outcomes.

Methods: A retrospective chart review of 25 patients with 29 ureteral strictures was performed to determine the success of their treatment.

Results: Twenty-five (25) patients with 29 benign ureteral strictures were identified. Most cases (60\%) were caused by impacted stones where the median stone size was $1.15 \mathrm{~cm}(0.37-1.8 \mathrm{~cm})$. Intervention for stones prior to stricture development included shockwave lithotripsy, URS, and percutaneous nephrolithotomy. Five patients with strictures from impacted stones had ureteric complications during stone treatment including perforation +/urinoma $(n=3)$, fractured guidewire left in situ $(n=1)$, and ureteric orifice resection $(n=1)$. Other stricture etiologies included radiation $(28 \%)$ and endometriosis (4\%). Treatment modalities used included ureteroureterostomy $(n=2)$, ureteral re-implant $(n=3)$, urinary diversion $(n=3)$, autotrasplant $(n=1)$, laser endoureterotomy $+/$ - balloon dilation $(n=8)$, nephrectomy $(n=2)$, balloon dilation $+/$ - stent $(n=3)$, ureterovesical junction (UVJ) resection + stent $(n=1)$, chronic stent changes $(n=4)$, or surveillance $(n=3)$.

Conclusions: Our evaluation highlights important principles. Patients with complicated ureteroscopies or severely impacted calculi warrant close followup with imaging after stone treatment due to possibility of rapid renal deterioration from stricture formation. Radiation-induced strictures are difficult to manage, possibly requiring subsequent urinary diversion. Finally, endoscopic management of benign ureteral strictures via balloon dilation and laser endoureterotomy is an excellent choice in properly selected patients, with opportunity for subsequent salvage treatments if needed.

\section{Introduction}

Ureteral strictures are narrowing of the ureter causing obstruction and are a significant cause of morbidity and mortality from renal failure. Benign strictures are typically caused by ischemia or inflammation. Causes include radiation, trauma from calculi impaction, pelvic surgery, or URS. Malignant strictures are the result of tumour infiltration and are not covered in this study. Traditionally, the open surgical treatment of ureteric strictures included ureteroureterostomy, ureteral re-implantation, +/- psoas hitch, +/- boari flap, +/renal decensus, ileal ureter, autotransplant, or nephrectomy. With the technological advances in endourology, endoscopic treatments, including balloon dilation, cold knife incision, and laser endoureterotomy are also being used. Success rates of endoscopic techniques have been reported to range from $46-89 \%$ and typically have benefits of decreased morbidity and hospital stay, with shorter recovery times. ${ }^{1-5}$ The objective of this study was to review our experience with benign ureteric strictures and assess the outcomes after management at our institution.

\section{Methods}

After obtaining approval from our institutional review board, we performed a retrospective chart review and identified 95 patients with a diagnosis of ureteral stricture between 2008 and 2013. Patients with stricture disease from ureteropelvic junction (UPJ) obstruction, malignancy, external compression, ureteroenteric anastomosis, and transplant ureteroneocystotomy, as well as patients with less than six months followup were excluded. Information on patient demographics, stricture length/location/etiology, presentation, management, complications and followup were collected. For patients with strictures due to impacted calculi, further information was collected regarding stone size, location, and type of stone intervention. 
Tran et al.

\section{Results}

Twenty-five (25) patients with 29 benign ureteral strictures were included (mean age 57 years; range 33-98 yrs; 8:17 male:female (32\%:68\%)). Stricture etiology is summarized in Table 1.

Most ureteral strictures $(60 \% ; 15 / 25)$ were related to urolithiasis. Of this subgroup, prior to stricture formation, three patients $(12 \%)$ had impacted stones but no prior ureteroscopy and were diagnosed with stricture disease at time of first ureteroscopy; seven patients (28\%) had uncomplicated ureteroscopy for stone treatment; and five patients (20\%) had URS for stone treatment with known complication (retained guidewire -1, perforation -3, and urinoma -1). Types of stone treatment intervention included ureteroscopy only $(40 \%$; 6/15); shockwave lithotripsy (SWL) and URS (47\%; 7/15); and percutaneous nephrolithotom and URS and (13\%; $2 / 15)$. Median stone size was $1.25 \mathrm{~cm}(0.37-1.8 \mathrm{~cm})$ for 12 cases and unknown in three cases. Intervention for stones prior to stricture development included SWL combined with URS $(61.5 \%)$, URS and percutaneous nephrolithotomy (12.5\%), URS only $(12.5 \%)$, and stone manipulation with ureteric orifice resection and deroofing (12.5\%). Half (50\%) of patients with strictures from impacted stones had ureteric complications during surgery for their stone, including perforation $(n=2)$, perforation with infected urinoma $(n=1)$, fractured ureteral guidewire left in situ $(n=1)$, and ureteric orifice resection $(n=1)$ (Table 2$)$.

The remainder of stricture etiology included radiation $(28 \% ; 7 / 25)$, endometriosis ( $4 \% ; 1 / 25)$, non-calculus-related iatrogenic injury $(4 \% ; 1 / 25)$, and unknown/idiopathic $(4 \%$; 1/25) (Table 1). The non-calculus-related iatrogenic injury was the result of transurethral resection of bladder tumour over the ureteric orifice with subsequent distal stricture formation. Stricture location was classified as proximal or distal relative to the sacroiliac joint (Table 3). Stricture length was separated into short $(\leq 1 \mathrm{~cm})$, long $(>1 \mathrm{~cm})$, and unknown (Table 3).

\begin{tabular}{lc}
\hline $\begin{array}{l}\text { Table 1. Ureteral stricture etiology is highly variable. The } \\
\text { majority of strictures were secondary to urolithiasis }\end{array}$ \\
\hline Stricture etiology & $\mathbf{N}=25$ \\
$\mathbf{n}(\%)$ \\
\hline Radiation & $7(28)$ \\
Endometriosis & $1(4)$ \\
Stone & $15(60)$ \\
Non-impacted & $0(0)$ \\
Impacted, no ureteroscopy & $3(12)$ \\
Ureteroscopy, no obvious complication & $7(28)$ \\
Ureteroscopy, known complication & $5(20)$ \\
latrogenic injury (Non-stone) & $1(4)$ \\
Unknown, idiopathic & $1(4)$ \\
\hline
\end{tabular}

Each patient was managed by one of four urologic surgeons with subspecialty training in urologic oncology, endourology, or renal transplantation. Treatment of strictures included in this review are outlined in Table 4. Of the eight patients treated with laser endoureterotomy, two required multiple endoscopic procedures, one had a subsequent nephrectomy, one had a subsequent ureteroureterostomy, and one had subsequent ureteral re-implant.

Followup imaging modalities varied depending on the treatment method undertaken. Patients were followed with postoperative serial creatinine and imaging ranging from one to 12 months after surgery and consisting of renal ultrasound ( $n=14)$, computed tomography (CT) abdomen/pelvis or CT kidney-ureter-bladder (KUB) $(n=6), C T$ intravenous pyelogram $(n=2)$, MAG3 renogram $(n=1)$, and pelvic magnetic resonance imaging (MRI) $(n=1)$. Those who underwent nephrectomy were followed at 12 months with imaging, but the remainder of patients undergoing endoscopic, ureteral reconstruction, or urinary diversion had postoperative imaging within one to six months. Four patients did not receive any postoperative imaging. Two of these patients were scheduled retrograde pyelogram evaluation during re-look URS and the other two were followed using serial creatinine only. Patients with ongoing flank pain, worsening hydronephrosis, or renal function underwent further diagnostic evaluation and intervention.

\section{Discussion}

Treatment of ureteric strictures focuses on preservation of renal function and symptom control, as well as minimizing morbidity and mortality. Our institutional review of patients with benign ureteral strictures revealed unique characteristics among patients with ureteric strictures from various etiologies that are important to highlight.

Radiation induces progressive microvascular injury and stromal fibrosis, leading to relative ischemia and subsequent stricture formation. Such radiation-induced ureteric strictures represent $28 \%$ of the strictures in our case series. Radiationinduced ureteric strictures have been reported in the medical literature since the 1920s. ${ }^{6}$ Interestingly, in 1987, Dauplat et al looked at brachytherapy radiation doses to the ureter in 16 patients treated for cervical cancer by inserting a radiopaque stent in their ureters. ${ }^{7}$ He found that $44 \%$ of these

\begin{tabular}{lc}
\hline $\begin{array}{l}\text { Table 2. Complications arising from endoscopic treatment } \\
\text { of urolithiasis }\end{array}$ \\
\hline Stone treatment complications & $\mathbf{n}$ \\
\hline Perforation & 2 \\
Perforation with infected urinoma & 1 \\
Fractured guidewire left in situ & 1 \\
Ureteric orifice resection & 1 \\
\hline
\end{tabular}


Table 3. Stricture location and length

\begin{tabular}{|c|c|}
\hline Stricture characteristics & $\begin{array}{l}\mathrm{N}=29 \\
\mathrm{n}(\%)\end{array}$ \\
\hline \multicolumn{2}{|c|}{ Location (Relative to sacroiliac joint) } \\
\hline Proximal & $7(24 \%)$ \\
\hline Distal & $21(72 \%)$ \\
\hline Complete & $1(3 \%)$ \\
\hline \multicolumn{2}{|l|}{ Length } \\
\hline Short $(\leq 1 \mathrm{~cm})$ & $6(21 \%)$ \\
\hline Long (>1cm) & $12(41 \%)$ \\
\hline Unknown & $11(38 \%)$ \\
\hline
\end{tabular}

patients had higher radiation doses to the ureter than the bladder or rectum.

Because of the relative ischemia to the entire radiation area surrounding the ureter, we found that these strictures were much more difficult to manage and treat. Four patients had cervical cancer, one patient had ovarian cancer, and two patients had rectal cancer with either primary or adjuvant radiotherapy. All three of the patients undergoing urinary diversion in our series had radiation-induced ureteric strictures. Of these, one patient had previously failed a ureteral re-implant and one developed an enterocutaneous fistula post-ileal conduit urinary diversion. Hence, patients with radiation-induced ureteral strictures require closer followup due to higher failure rates. Also, endoureterotomy has been shown to be less successful in this cohort of patients and consideration for more definitive open surgical reconstruction is suggested from the onset of presentation. ${ }^{8}$

Although radiation-induced ureteric strictures are challenging to manage, stone-related strictures comprised the majority of strictures in our series. Significant risk factors for stricture formation in this group include stone impaction greater than two months, urinary perforation, and embedded calculi within the ureteral lumen. ${ }^{9}$ Seven of 15 patients $(47 \%)$ in our series developed ureteric strictures following seemingly uncomplicated ureteroscopy for stone disease. Various groups have reported post-ureteroscopy stricture rates ranging from $0-4 \%$ of all ureteroscopies. ${ }^{10-12}$ Because ureteric strictures can develop even after seemingly uncomplicated endoscopic treatment of urolithiasis, an important consideration is whether or not routine postoperative imaging is needed following all ureteroscopies.

Weizer et al looked at 241 patients treated for renal and ureteral calculi; ${ }^{13} 30$ patients developed postoperative obstruction ( 25 from residual calculi and three from stricture disease). Seven of the 30 patients had completely silent and asymptomatic obstruction, with one patient even going on to requiring hemodialysis for chronic renal failure. Hence, those authors suggest routine renal ultrasound or cross-sectional imaging within three months of ureteroscopy.

Adiyat et al defined complicated ureteroscopies as those with ureteral perforation, impacted stone, need for balloon

\begin{tabular}{lc} 
Table 4. Treatment modalities of ureteral strictures \\
\hline Treatment modality & $\mathbf{N}=\mathbf{2 5}$ \\
& $\mathbf{n}$ \\
Surveillance & 3 \\
Balloon dilation +/- ureteric stent & 3 \\
Laser endoureterotomy +/- balloon & 8 (2 required multiple \\
dilation & endoscopic procedures) \\
Transurethral resection of UVJ + & 1 \\
ureteric stent & 2 (1 after failed \\
Nephrectomy (MIS/open) & endoureterotomy) \\
Open ureteroureterostomy & 2 (1 after failed \\
Open ureteral re-implant & endoureterotomy) \\
Urinary diversion & 3 (1 after failed \\
lleal conduit & endoureterotomy) \\
Indiana & 3 \\
Nephroureterectomy + ileal conduit & 1 \\
Autotransplant & 1 (after failed ureteral \\
Ongoing chronic stent changes & reimplant) \\
\hline
\end{tabular}

MIS: minimally invasive surgery; UVJ: ureterovesical junction.

dilation, or flank pain post-stent removal. ${ }^{11}$ He examined 214 patients with renal and ureteral calculi treated with ureteroscopy. All had CT KUB $\geq 1$ month post-ureteroscopy. The ureteric stricture rate was $5.4 \%$ in those with complicated ureteroscopy vs. those with uncomplicated ureteroscopy. Thus, we may be able to reserve postoperative imaging to only these scenarios.

One patient in our series underwent URS for an impacted UPJ calculus and the case was complicated by ureteral perforation and stone extravasation. This patient had a ureteric stent for a month and had a retrograde pyelogram showing no stricture at time of stent removal. Within three months, however, the kidney became atrophic and the patient required nephrectomy. Hence, silent obstruction is a real problem that requires vigilant followup, especially in cases of complicated ureteroscopy. Kidney damage can occur very quickly following ureteral stricture development.

Regardless of the initial etiology of stone formation, the management options for patients with ureteral stones are numerous. One of the less invasive treatment options for ureteral strictures includes balloon dilation and endoureterotomy. With advancements in endourologic instrumentation, Ho:YAG laser endoureterotomy is a popular choice. Advantages include precise incision of the stricture under direct visualization, minimal collateral and peripheral damage, and the ability to perform this using a flexible ureteroscope. Reported success rates vary from $55-85 \%$, depending on the stricture site and etiology. ${ }^{8,14-17}$

All eight patients undergoing endoureterotomy in our case series were treated with Ho:YAG laser. Of these, five patients 
Tran et al.

were treated successfully with $\leq 2$ endoscopic surgeries. One patient with endometriosis was treated with laser endoureterotomy, but continued to have ongoing flank pain, as well as a Lasix renal scan showing mild obstruction. Five months later, the patient underwent open ureteral re-implant and has been doing well since, with no obstruction or symptoms.

One patient with recurrent ureteral stone disease was treated with uncomplicated URS and subsequently developed a distal ureteral stricture. She received two ureteral balloon dilatations and subsequent laser endoureterotomy. Unfortunately, she had ongoing severe flank pain and, despite periodic imaging and bloodwork showing stable hydronephrosis and renal function, her kidney atrophied one year post-laser endoureterotomy and she subsequently received laparoscopic nephrectomy.

Another patient with ureteral stricture from impacted stones failed laser endoureterotomy and went on to have an open segmental ureterectomy and ureteroureterostomy. Our success rate for laser endoureterotomy are similar to that reported in the literature, but it is a good option for patients unable to tolerate more invasive surgical intervention, and is a reasonable first-choice treatment option. It is particularly more successful in those with shorter strictures $(<1 \mathrm{~cm})$. Patients who fail endoscopic treatment still have the opportunity for other treatment options. ${ }^{18,19}$ Success rates are higher for non-ischemic structures (not due to surgery, radiation or stone impaction), shorter strictures $(\leq 1 \mathrm{~cm})$, and strictures located at the extremes of the ureter (UPJ or UVJ due to improved blood supply). ${ }^{4,8}$ Poor ipsilateral renal function $(<25 \%)$ appears to negatively impact endoureterotomy success rates.

Our study identified patients with ureteral stricture disease from a wide variety of etiologies and assessed how they were managed and treated. Study limitations include that it was a retrospective study, with possible collection bias; multiple urologists with varying subspecialty training were involved in treating different patients; and not all characteristic information was available from every patient.

\section{Conclusion}

The management of benign ureteral strictures is complex due to varying stricture etiology, length, location, and patient factors. Our evaluation highlights important principles. Impacted ureteral calculi are the most common risk factor for ureteral stricture formation. Patients with complicated ureteroscopies or severely impacted calculi warrant close followup with imaging after stone treatment due to possibility of rapid renal deterioration from stricture formation. Radiation-induced strictures are very difficult to manage, and these patients may require subsequent urinary diver- sion. Finally, endoscopic management of benign ureteral strictures via balloon dilation and laser endoureterotomy is an excellent choice in properly selected patients, with opportunity for subsequent salvage treatments if needed.

Competing interests: The authors declare no competing financial or personal interests.

This paper has been peer-reviewed.

\section{References}

1. Corcoran AT, Smaldone MC, Ricchiuti DD, et al. Management of benign ureteral strictures in the endoscopic era. J Endourol 2009; 23:1909-12. http://dx.doi.org/10.1089/end.2008.0453

2. Richter $F$, Irwin RJ, Watson RA, et al. Endourologic management of benign ureteral strictures with and without compromised vascular supply. Urology 2000; 55:652-7. http://dx.doi.org/10.1016/S00904295(00)00484-2

3. Netto Junor NR, Ferreira U, Lemos GC, et al. Enduorlogical management of ureteral strictures. J Urol 1990;144:631-4.

4. Wolf JS Jr, Elashry OM, Clayman RV, et al. Long-term results of endoureterotomy for benign ureteral and ureteroenteric strictures. J Urol 1997;158:759-64. http://dx.doi.org/10.1016/S0022-5347(01)64308-8

5. Meretyk S, Albala DM, Clayman RV, et al. Endoureterotomy for treatment of ureteral strictures. J Urol 1992;147:1502-6.

6. Mclntyre JF, Eifel PJ, Levenback $C$, et al. Ureteral stricture as a late complication of radiotherapy for stage IB carcinoma of the uterine cervix. Cancer 1995; 75:836-43. http://dx.doi.org/10.1002/10970142(19950201)75:3<836::AID-CNCR2820750315>3.0.C0;2-A

7. Dauplat J, Archard JL, Donnarieix D, et al. La dosimétrie urétérale en curiethérapie gynécologique. J Urol (Paris) 1987;93:123-7.

8. Gnessin E, Yossepowitch 0 , Holland R, et al. Holmium laser endoureterotomy for benign ureteral stricture: A single-centre experience. J Urol 2009;182:2775-9. http://dx.doi.org/10.1016/i.juro.2009.08.051

9. Roberts WW, Cadeddu JA, Micali S, et al. Ureteral stricture formation after removal of impacted calculi. J Urol 1998;159:723-6. http://dx.doi.org/10.1016/S0022-5347(01)63711-X

10. Harmon WJ, Sershon PD, Blute ML, et al. Ureteroscopy: Current practice and long-term complications. J Urol 1997; 157:28-32. http://dx.doi.org/10.1016/S0022-5347(01)65272-8

11. Adiyat KT, Meuleners R, Monga M. Selective postoperative imaging after ureteroscopy. Urology 2009;73:490-3. http://dx.doi.org/10.1016/i.urology.2008.09.064

12. Krambeck AE, Murat FJ, Gettman MT, et al. The evolution of ureteroscopy: A modern single-institution series. Mayo Clin Proc 2006;81:468-73. http://dx.doi.org/10.4065/81.4.468

13. Weizer AZ, Auge BK, Silverstein AD, et al. Routine postoperative imaging is important after ureteroscopic stone manipulation. J Urol 2002;168:46-50. http://dx.doi.org/10.1016/S0022-5347(05)64829-X

14. Gdor Y, Gabr AH, Faerber GJ, et al. Success of laser endoureterotomy of ureteral strictures associated with ureteral stones is related to stone impaction. J Endourol 2008; 22:2507-11. http://dx.doi. org/10.1089/end.2008.0387

15. Lane BR, Desai MM, Hegarty NJ, et al. Long-term efficacy of holmium laser endoureterotomy for benign ureteral strictures. Urology 2006; 67:894-7. http://dx.doi.org/10.1016/i.urology.2005.11.012

16. Patel RC, Newman RC. Ureteroscopic management of ureteral and ureteroenteral strictures. Urol Clin $N$ Am 2004;31:107-13. http://dx.doi.org/10.1016/S0094-0143(03)00092-2

17. Hibi H, Ohori T, Taki T, et al. Long-term results of endoureterotomy using a holmium laser. Int I Urol 2007;14:872-4. http://dx.doi.org/10.1111/i.1442-2042.2007.01835.x

18. Kramolowsky EV, Tucker RD, Nelson CM, et al. Management of benign ureteral strictures: Open surgical repair or endoscopic dilation? J Urol 1989;141:285-6.

19. Fasihuddin $Q$, Abel $F$, Hasan AT, et al. Effectiveness of endoscopic and open surgical management in benign ureteral strictures. J Pak Med Assoc 2001;51:351-3.

Correspondence: Dr. Henry Tran, University of British Columbia, Vancouver, BC, Canada; henryhył@gmail.com 